\title{
A TERAPIA ASSISTIDA POR ANIMAIS (TAA) E A PSICOLOGIA: UM ESTUDO FENOMENOLÓGICO DAS DIFERENTES MODALIDADES DE VÍNCULOS ENTRE HUMANOS E DEMAIS ANIMAIS NA TERAPÊUTICA
}

\author{
ANIMAL ASSISTED THERAPY (AAT) AND PSYCHOLOGY: A \\ PHENOMENOLOGICAL STUDY OF THE DIFFERENT BONDING MODALITIES \\ BETWEEN MAN AND OTHER ANIMALS IN THERAPEUTICS
}

\section{LA TERAPIA ASISTIDA POR ANIMALES (TAA) Y LA PSICOLOGÍA: UN ESTUDIO FENOMENOLÓGICO DE LAS DIFERENTES MODALIDADES DE VÍNCULOS ENTRE HOMBRE Y DEMÁS ANIMALES EN LA TERAPÉUTICA}

\author{
Felipe Fook Bastos ${ }^{1}$ \\ Jean Marlos Pinheiro Borba ${ }^{2}$ \\ 10.21665/2318-3888.v6n11p242-267
}

\begin{abstract}
RESUMO
A pesquisa desenvolvida teve como alvo o fenômeno das relações entre humanos e demais animais, investigando as diferentes modalidades e manifestações dessa relação, bem como o processo de criação do vínculo entre humanos e demais animais, dando um enfoque em como essas relações e vínculos permitem um processo terapêutico e quais as consequências e desdobramentos desse processo (TAAs). A pesquisa é qualitativa e consistiu em uma pesquisa bibliográfica, na qual foram evidenciados na literatura diferentes modalidades de vínculos e suas implicações. O modelo metodológico utilizado foi a fenomenologia husserliana, proposta e fundada pelo filósofo e matemático Edmund Husserl. A fenomenologia consiste em um modelo de pesquisa radical e rigoroso que visa constituir uma ciência universal das essências através da suspensão dos apriores e da crítica à postura ingênua/natural, evidenciando o fenômeno tal qual ele se mostra. Desse modo, a pesquisa teve como resultado a descrição e compreensão de diferentes modalidades da relação entre humanos e demais animais com finalidades terapêuticas, sendo a primeira uma modalidade que anula o animal enquanto outro e o assume no lugar de um objeto, recurso e instrumento, perdendo qualquer implicação de uma conduta ética sobre eles, o que resulta na manifestação de atos de crueldade, abandono, experimentações cruéis e sem objetivos e etc; enquanto a segunda apresenta um modo de relação na qual o animal é reconhecido enquanto outro, e esse reconhecimento permite a manifestação de empatia, alteridade e respeito. Fora isso, as duas modalidades apresentam diferentes horizontes de possibilidade para o desdobramento e para a compreensão do processo terapêutico. Enquanto a primeira, condizente com o modo de pesquisa das ciências naturais, foca em aspectos mensuráveis, tentando justificar o evidente bem que os animais nos causam, e perdendo de vista uma série de fenômenos; a segunda consiste na apreensão e compreensão desse fenômeno tal como ele se manifesta e evidência na vida, permitindo-nos intuir uma série de fenômenos, outrora encobertos, para um processo terapêutico mais rico, consciente e eficiente.
\end{abstract}

Palavras-chave: Terapia Assistida por Animais - TAAs. Fenomenologia. Relação.

\footnotetext{
${ }^{1}$ Graduando em Psicologia (UFMA). E-mail: felipe.fook.b@gmail.com.

2 Doutor em Psicologia Social (UERJ). Professor do Departamento de Psicologia e professor permanente do Mestrado em Psicologia (UFMA). E-mail: jean.marlos@ufma.br.
} 


\begin{abstract}
The research developed was aimed at the phenomenon between man and other animals relations, investigating the different modalities and manifestations of this relationship, as well as the bonding process creation between man and other animals, focusing on how these relationships and bonds allow a therapeutic process and what the consequences of this process (TAAs). The qualitative approach consisted of a bibliographical research, in which different types of links and their implications were evidenced. The methodological model used was the husserlian phenomenology, proposed and founded by the philosopher and mathematician Edmund Husserl. Phenomenology consists of a radical and rigorous research model that seeks to constitute a universal science of the essences by suspending apriori and criticism replacing by a naive / natural posture, evidencing the phenomenon as it is shown. The research resulted in a description and understanding of different modalities of relationship between man and other animals for therapeutic purposes, the first of them, a modality that annuls the animal as a self and takes it rather as an object, resource or instrument, in a demonstration of devoid of a more conscious ethical sense conduct, which results in the manifestation of acts of cruelty, abandonment, cruel and objective experiments etc.; while the second one presents a mode of relationship in which the animal is recognized as a self, allowing empathy, otherness and respect manifestation. Thus, the two modalities present different horizons of possibility for unfolding and for understanding the therapeutic process. While the first one, consistent of the natural sciences mode of research, focusing on measurable aspect, trying to justify the evident good that animals cause us, and losing sight of a series of phenomena; the second consists in the apprehension and understanding of this phenomenon as it manifests and evidence in life, allowing us to intuit a series of phenomena, once hidden, for a richer, more conscious and efficient therapeutic process.
\end{abstract}

Keywords: Animal-Assisted Therapy - TAAs. Phenomenology. Relationship.

\title{
RESUMEN
}

La investigación realizada tuvo como objetivo el fenómeno de las relaciones entre hombre y demás animales, investigando las diversas formas y manifestaciones de la relación y el proceso de creación de vínculo entre hombre y demás animales, dando un enfoque en cómo esas relaciones y vínculos permiten un proceso terapéutico y cuáles son las consecuencias y desdoblamientos de este proceso (TAA). La investigación es cualitativa y consistió en una investigación bibliográfica, en la cual diferentes modalidades de vinculación y sus implicaciones fueron evidenciadas en la literatura. El modelo metodológico utilizado fue la fenomenología husserliana, propuesta y fundada por el filósofo y matemático Edmund Husserl. La fenomenología es una investigación radical y rigurosa que tiene por objetivo la construcción una ciencia universal de las esencias a través de la suspensión de los a priori y crítica a la postura ingenua / natural, evidenciando el fenómeno como se muestra. Así, la investigación resultó en la descripción y comprensión de diferentes tipos de relación entre hombre y demás animales para fines terapéuticos, siendo el primero un modo que anula al animal en cuanto otro y lo asume, en lugar de un objeto, recurso e instrumento perdiendo cualquier implicación de conducta ética sobre ellos, lo que resulta en la manifestación de actos de crueldad, abandono, experimentos crueles y sin objetivos, etc.; mientras que el segundo presenta un modo de relación en que el animal es reconocido como otro, y ese reconocimiento permite la manifestación de empatía, alteridad y respeto. Además, las dos modalidades presentan diferentes horizontes de posibilidad para el desdoblamiento y para la comprensión del proceso terapéutico. Mientras el primero, de acuerdo con el modo de investigación de las ciencias naturales, se concentra en aspectos mensurables, intentando justificar el bien evidente que los animales nos causan, y perdiendo de vista una serie de fenómenos; el segundo es la aprehensión y comprensión de este fenómeno que se manifiesta y es evidenciada en la vida, nos permite intuir una serie de fenómenos, no manifiestos, para proceso terapéutico más, consciente y eficiente.

Palabras clave: Terapia Asistida por Animales - TAAs. Fenomenologia. Relación. 


\section{Introdução}

As Terapias Assistidas por Animais já são uma prática e um procedimento terapêutico reconhecido no mundo, praticado e legitimado em diversos países e que vem ganhando espaço. Segundo as estatísticas para o ano de 2004 acerca dos procedimentos de AAA e TAA era de: 6.400 grupos atuando em 50 estados norte-americanos e quatro países, ajudando cerca de 1 milhão de pessoas (DOTTI, 2014).

Demonstrada a magnitude e a amplitude que as TAA's alcançaram, tornou-se imprescindível buscar um enfoque na relação entre humanos e animais como fenômeno basilar para a proposta terapêutica dessa prática.

Dessa forma, a pesquisa objetivou compreender os aspectos do desenvolvimento e as modalidades do vínculo entre seres humanos e os demais animais, de modo a elucidar de que maneira esse vínculo possui uma ação terapêutica, quais suas características essenciais, quais modalidades de vínculos são mais desejáveis.

Corrobora para a necessidade da pesquisa a atual relação contemporânea dos seres humanos com os demais animais, o que põe em questão a ética com os seus limites e alcances. É notada que a relação do ser humano com os demais animais tem passado por diversas mudanças. Assim, é preciso que se ponha em questão o lugar no qual colocamos os demais animais no momento em que nos relacionamos com eles.

De maneira que traz para o plano reflexivo a nossa conduta em relação aos demais animais, evidenciando como eles na contemporaneidade, perderam seu lugar de reconhecimento e valor, e tornaram-se objetos. Dessa forma, acrescenta-se assim, a prerrogativa de que é preciso compreender como e se é possível uma prática terapêutica com o animal objetificado.

Portanto, é preciso compreender e apreender os caminhos e processos que levam à objetificação animal. Assim, também é necessário conhecer e entender o que se tem feito acerca das terapias com animais, com uma visão crítica. Entender se existe um vínculo entre os seres humanos e os demais animais nos atuais modelos de TAAs, e quais as implicâncias de uma prática terapêutica com um animal na posição de objeto e desvendar novos caminhos e possibilidades mais éticas, humanas e eficientes. 
Em suma, a pesquisa voltou-se para o fenômeno das TAAs, em especial na sua relação com a psicologia, e para o vínculo milenar entre seres humanos e demais animais. Não obstante, buscou-se por compreender e descrever os processos que possibilitam uma relação de vínculo e como esse vínculo tem um potencial terapêutico.

Assim, a pesquisa teve como orientação epistemológica, teórica e metodológica a Fenomenologia, em especial com a Fenomenologia e a Psicologia Fenomenológica desenvolvida e fundada por Edmund Husserl (1859-1938), que não só tem uma preocupação epistemológica visando à construção de um conhecimento mais rigoroso, como também tem a ética como preocupação central em seu pensamento.

\section{Referêncial teórico}

\subsection{A fenomenologia husserliana}

O referencial teórico e metodológico escolhido para análise do fenômeno foi a fenomenologia de base husserliana, ou seja, desenvolvida e fundada por Edmund Husserl (1859-1938). Edmund Husserl foi um dos mais proeminentes pensadores do século XX, foi filósofo e matemático que influenciou diversas correntes filosóficas e científicas, de seu tempo e até a atualidade (GOTO, 2007).

A fenomenologia husserliana é rigorosamente uma ciência universal das essências dos fenômenos que aparecem à consciência intencional. Para tanto, baseia-se primordialmente em uma crítica epistemológica ao naturalismo que busca, não só constituir uma ciência rigorosa que consiga dar conta daquilo que a ciência de ordem naturalística não consegue contemplar, mas também, ao fazer isso, reinstituir e restaurar o sentido do conhecimento (HUSSERL, 1965; 2000).

Em suma, a fenomenologia enquanto método e postura epistemológica contrapõe-se ao que historicamente é conhecido como naturalismo. O naturalismo é um modo de relacionar-se com o mundo pautado e propiciado pelas ciências naturais. Em suma, o naturalismo, segundo Guimarães (2013), defende que tudo que existe é pertencente à 
natureza e, portanto, pode ser explicado pelas ciências naturais, tais como a física, a química e a biologia.

Em contrapartida, tal prerrogativa conduz-nos a uma existência na qual nós nos distanciamos da vida e do mundo. A ciência e esses conhecimentos acerca do funcionamento da realidade antepõe-se à vivência, a experimentação do que é o mundo e, portanto causa um distanciamento desse mundo, que outrora era vívido.

Dessa maneira, a ciência natural, ao antepor-se à vida, encontra-se enquanto a priori, um conhecimento prévio tomado enquanto verdade, que ofusca o sentido do conhecimento. De forma que a fenomenologia, ao impor um maior critério epistemológico evidencia tais aspectos importantes para a pesquisa: altera a relação entre sujeito e objeto; métodos que nos permitem desvendar o sentido do conhecimento, um conhecimento mais rigoroso e acesso ao mundo-da-vida; constituir uma epistemologia que permita a inclusão de um horizonte ético e humanizado, que vá contra a crise da racionalidade ocidental.

Assim, pode-se conceber essas quatro etapas que elucidaram como a pesquisa foi realizada. A primeira etapa sendo referente à relação estritamente epistemológica e única ratificada pela fenomenologia entre sujeito-objeto, de modo a romper essa dicotomia; a segunda etapa consiste em explicar alguns meios e procedimentos - não meramente técnicas- que permitem o acesso e a compreensão a esse conhecimento; a terceira é uma discussão que envolve a perspectiva da crise gerada pelo naturalismo, suas implicações e a restauração do sentido do conhecimento para a humanidade; e a quarta, em como esses processos foram utilizados em uma pesquisa bibliográfica e qualitativa.

Por isso, é importante partir de Husserl visto que ele inicia seu caminho epistemológico através da Matemática passando pela Psicologia e Filosofia (HUSSERL, 1965). Em sua época existiam dois movimentos epistemológicos concorrentes: o logicismo e o psicologismo que diziam respeito às concepções dominantes acerca da natureza e da origem das leis da lógica e de seu estudo sobre a Psicologia (GOTO, 2015). 
Os psicologistas afirmavam que as leis da lógica poderiam ser explicadas através dos processos psicológicos, e, portanto, da psicologia natural, pautada na química, na física e na biologia. Por outro lado, os logicistas afirmavam que a lógica e suas leis eram alheias aos processos psicológicos, e que existiam independentemente desses (GOTO, 2015).

Dessa maneira, essa questão logo põe em xeque a concepção do conhecimento. Pois as leis lógicas decorreriam dos processos inerentes ao próprio pensar, ao próprio res cogitans, ou antes, não deveria daí decorrer a sua existência. Diante dessa questão primordial, fica perceptível que a relação com o conhecimento estava posta em xeque. Afinal, ou o conhecimento seria originário das leis do pensamento, explicáveis pela Psicologia, ou antes, algo para além de tais processos psicológicos. Husserl se opôs a tentativa de transformar as leis do pensamento em leis naturais do pensamento conforme preconizavam os psicologistas.

Assim, um problema nascido na matemática e na aritmética, que tinha a lógica como fundamento, passa para o campo da epistemologia, da filosofia e da psicologia. Dessa maneira a preocupação primária e originária da fenomenologia é, antes de tudo, a epistemologia e sua possibilidade.

Dessa forma, Husserl (2014) elabora a perspectiva inicial de que a Psicologia e a Lógica teriam ambas por objeto estudar as leis dos diversos gêneros de representações, juízos, silogismos e etc. Contudo, lei para ambas as disciplinas tem um significado diferente: a psicologia deveria investigar as leis das conexões reais entre si dos processos de consciência, as disposições psíquicas associadas e os processos correspondentes no organismo corpóreo; enquanto a lógica deveria ocupar-se das leis que devem decorrer para que os juízos sejam verdadeiros.

\subsection{O método fenomenológico}

Dito isto, o caminho para o conhecimento deveria, portanto, seguir dos dados verdadeiros, apodíticos, para que, então, pudesse se construir um conhecimento e juízos verdadeiros. Logo, o conhecimento que daí nasce seria, portanto, mais seguro e com o 
sentido já apreendido. Estabelece-se então a crítica à teoria do conhecimento, e esta crítica é a fenomenologia (HUSSERL, 2000).

Portanto, diferentemente do método das ciências naturais, o conhecimento não deveria partir do ceticismo, da dúvida - que outrora foi instaurada pela concepção da ciência natural. Afinal, estaria aí um contrassenso, pois se esse é um esforço para construir um conhecimento não se deveria duvidar da existência do ato de conhecer, descartando-o e pondo-o em contradição lógica, mas ao contrário acatando-o no seu aparecimento imediato.

Afinal, é essa uma das questões que Husserl coloca em A idéia da fenomenologia (2000), o motivo de porque alguns conhecimentos são passíveis de questionamento e outros, axiomáticos, são postos como inquestionáveis. E então Husserl (2000) aplica dois termos que em seu pensamento ocuparam posições importantes, a imanência e a transcendência. O conhecimento imanente, próprio do cogito, não é questionável, pois é autoevidente; enquanto os conhecimentos das ciências objetivas, naturais, são transcendentes, estão fora do cogito, e por isso, são possíveis de dúvida.

Desse modo, avançando, Husserl (2000) consegue levar adiante a concepção e a perspectiva de um pensamento, não mais contraditório e que pode ser posto em dúvida, mas sim pautado na evidência própria. Não se trata da exclusão do verdadeiramente transcendente, mas sim, do transcendente em geral; ou seja, de tudo que não é dado evidente no sentido genuíno, mas também não se fixa na imanência; fica, portanto, em suspenso todos esses conhecimentos, e os dados são aceitos enquanto fenômenos.

Deste modo é possível a: "[...] capitação do sentido da evidência absolutamente intuitiva, que a si mesma se apreende" (HUSSERL, 2000, p. 29). Para tanto, a fenomenologia compreende que: "o conhecimento pertence à esfera das cogitationes, [...], temos de elevar intuitivamente à consciência da universalidade as objectalidades universais dessa esfera, e tornar-se possível uma doutrina de essência do conhecimento" (HUSSERL, 2000, p. 28). O que também garante uma nova objetividade, a objetividade das essências. 
Ao trabalhar a dualidade já apresentada entre a imanência e a transcendência, inaugurase uma nova relação entre o sujeito cognoscente e o conhecimento. O sujeito conhece através de sua consciência intencional que é sempre consciência de algo. É a existência de uma essência que permite que ela intua o fenômeno, que se manifesta para a consciência, sendo a essência um tipo conceitual, ou seja, algo em comum, geral, presente e autoevidente nas manifestações fenomênicas (ZILLES, 2008).

Desse modo, com a consciência sendo sempre a consciência de algo, compreendemona enquanto um ato se dirige para algo, portanto, não existe consciência sem objeto ao qual ela se dirige. Nessa perspectiva rompe-se com o dualismo sujeito-objeto, pois não existe um sem o outro. Todo sujeito é para um objeto e todo objeto está para um sujeito sempre em relação. É inaugurada então na fenomenologia à concepção de noesis, enquanto vivência do ato de percepção; e noema, enquanto correlato intencional da vivência (BARBOSA, 2014). Essa relação é conhecida como noético-noemática.

Assim, podemos compreender como e por meio de quais caminhos é possível a apreensão da essência e a constituição desse conhecimento mais rigoroso, que propõe a volta às coisas mesmas. Para tal finalidade, dever-se-á atentar-se aos métodos, e entendamos aqui, métodos em seu sentido original, que etimologicamente significa caminho (BARBOSA, 2006).

Portanto, a fenomenologia parte da vivência própria do mundo, alcançando-se assim o mundo vivido, e para isto existem os caminhos: as reduções e a epoché. Que embora tomadas corriqueiramente enquanto sinônimas, nem sempre o são. De todo modo a epoché consiste na suspensão dos conhecimentos e juízos prévios sobre determinado assunto (CASTRO; GOMES, 2011).

Dito isto, torna-se oportuno explicar alguns aspectos importantes da teoria husserliana. Desse modo, a redução fenomenológica, que nos permitem chegar às essências das coisas mesmas, é descrita por Guimarães (2013), sendo dividida didaticamente em três etapas. Em suma, as etapas são: a redução psicológica, a redução eidética e a redução transcendental. 
A redução psicológica consiste na colocação do mundo entre parênteses que nos leva a entender que existe uma infinidade de sentidos da manifestação de um fenômeno (GUIMARÃES, 2013). Essa é a primeira redução e foca-se no caráter descritivo da experiência do fenômeno, busca uma abstenção do que já se sabe, e dos juízos prévios, contemplando a experiência empírica do sujeito, mas não as concepções explicativas naturalísticas; nela é realizado o movimento da epoché (CASTRO; GOMES, 2011).

A redução eidética possibilita descrever a essência do fenômeno permitindo que se apreenda via apreensão cognoscente o fenômeno, bem como suas características essências que são percebidas pela consciência intencional. Para tal redução podemos utilizar a reflexão e o método da variação imaginativa. Esse método consiste em variar elementos da manifestação do fenômeno, de modo que este não se perca. Em outras palavras, consiste em imaginar várias variações no fenômeno, até que se encontra a essência daquele fenômeno (CASTRO; GOMES, 2011).

Na redução transcendental, as essências são vivenciadas e evidenciadas na ordem da consciência transcendental. É aqui que o sentido do fenômeno é revelado pela consciência (GUIMARÃES, 2013). Entenda-se que quando Husserl aborda o termo transcendental ele refere-se ao "mundo interior" - outrora, imanente; e quando se refere à transcendente, refere-se ao "mundo externo" (ZILLES, 2008). Resta observar que a fenomenologia husserliana não há separação entre mundo interno e mundo externo, pois todos eles compõem o mundo-da-vida.

Desse modo, compreende-se como Husserl supera as dualidades interno-externo e sujeito-objeto (ZILLES, 2007). Pois trazendo o fenômeno para a compreensão enquanto um fenômeno apreendido em um ato de consciência, admite-se que a experiência direta e imediata seja a forma de contato com o conhecimento, não se constituindo como um mero empirismo, mas sim, apreender por meio de uma série de procedimentos como o fenômeno é intuído pela consciência que o intui, e é nesse ponto que incide o rigor teórico da fenomenologia (GOTO, 2015).

Nesse ponto, não se deve conceber que Husserl desconsidere a realidade externa do mundo, mas para a fenomenologia, só existe conhecimento se ele estiver em relação direta com uma consciência, com um sujeito cognoscente. Para Husserl, o real remete 
a um fenômeno que tenha uma manifestação no tempo e no espaço e que esteja sujeito às leis causais (GIORGI, 2005).

Assim, os modelos atuais da ciência se debruçam sobre objetos do mundo externo, e conseguem avanços e conhecimento através do empirismo sistematizado do modelo científico natural (FERREIRA, 2008). Desse modo, a metodologia das ciências naturais não só oculta aquilo que é da relação imediata com o objeto que é intencionado, uma vez que esse é compreendido a partir de conhecimentos prévios, como também impõe um limite para essa epistemologia (FEIJOO; GOTO, 2016). Assim, por exemplo, ao lidar com a experiência de fenômenos quase reais ou irreais, ou seja, que não atendam os critérios dos fenômenos reais, como, por exemplo, a imaginação, o pensamento, a cultura, a religião, a fé e etc. (GIORGI, 2005).

Outros modelos epistemológicos também foram criticados por falta de rigor e por restringir a epistemologia a objetos específicos, de modo que a fenomenologia surge como uma ciência universal, daquilo que é o dado objetivo de qualquer fenômeno: a essência. Outro modelo epistemológico criticado, por exemplo, foi o historicismo que implicaria sempre em um relativismo, e não em uma verdade universal (HUSSERL, 1965).

Entretanto, é oportuno sinalizar que para essa proposta epistemológica o "[...] objetivo não é uma física, mas uma ética do pensar" (HUSSERL, 2014, p.42). Ou seja, é evidente que o fundamento do rigor científico na fenomenologia husserliana "[...] está na ordem ética. A crise não decorre de uma fragilidade do caráter metodológico da cientificidade, mas na perda do sentido das ciências para a existência humana. E a causa fundamental desta perda é o seu afastamento do mundo-da-vida" (CAVALIERI, 2010, p. 648).

Assim, é concebível o que Husserl (2008) determina enquanto crise. A tomada da cena da racionalidade europeia pelo naturalismo fez com que se desconsiderassem as prerrogativas de uma razão verdadeiramente virtuosa. $O$ apego à materialidade, ao objetivismo, objetificou o pensamento e a consciência, naturalizando-a.

Abre-se, então, espaço para a barbárie e para a fobia, e decai a civilização perante de tais ameaças, o projeto da racionalidade deve voltar à vida e a encarar o ser humano em 
toda sua humanidade, e não como moléculas e átomos frios aos observadores de microscópios.

\section{O caminho metodológico percorrido}

Assim, essa pesquisa consistiu em uma pesquisa bibliográfica, realizada com fontes oriundas do meio bibliográfico e virtual. O meio virtual composto por bancos de dados como repositórios on-line de universidades, Google acadêmico e Scielo; o meio bibliográfico representa acervo dos pesquisadores e livros e periódicos acessado em bibliotecas na cidade de São Luís- MA.

É, portanto, uma pesquisa qualitativa na medida em que se ocupa de sistematizar as informações e também de descrevê-las, sem interesse em quantificá-las e que: "[...] implica em um conjunto ordenado de procedimentos de busca por soluções, atento ao objeto de estudo, e que, por isso, não pode ser aleatório" (NEVES, 1996, p.1).

De modo que a pesquisa se baseou no modelo de pesquisa fenomenológica desenvolvida na Duquesne University - sistematização técnica dos postulados lógicose nos setes passos sugeridos para aplicação da pesquisa fenomenológica nas ciências humanas, contudo, adequando-se à realidade da pesquisa sem contradizer os postulados lógicos e teóricos que os embasam (CASTRO; GOMES, 2011).

Portanto, a pesquisa consistiu nas seguintes etapas: delimitação do fenômeno pesquisado; leitura do material realizada através das reduções fenomenológicas; investigação de essências gerais; apreensão de relações essenciais entre constituintes do fenômeno; observação dos modos de aparecimento do fenômeno; divisão textual em unidades de significado com base no contexto geral de enunciação de cada texto e na análise das unidades de significado.

Dessa maneira, observa-se que, metodologicamente, o fenômeno pesquisado e delimitado foram os modos de vínculos entre humanos e demais animais dentro dos processos terapêuticos. Desse modo, a leitura dos materiais foi realizada seguindo as reduções fenomenológicas; em especial, durante a etapa da redução eidética, foram 
delimitados as essências dos fenômenos intencionados. Uma vez delimitadas as estruturas essenciais dos fenômenos da TAA, do vínculo e da terapêutica foram apreendidas as relações entre esses fenômenos, em especial nas suas manifestações na própria literatura.

Uma vez delimitadas as estruturas essenciais dos fenômenos intencionados, apreendidas as suas relações e observadas diretamente (epoché) na sua própria manifestação na literatura, pode-se dividir os modos de aparecimento dos fenômenos em unidades de significados e em suas análises. Convergindo, assim, para a compreensão dos fenômenos tal qual eles se evidenciam e quais os seus sentidos originários.

\section{Resultados e discussões}

Mediante a perspectiva husserliana evidenciaram-se duas principais modalidades de relação entre os seres humanos e os demais animais. Essas modalidades estão presentes na literatura pesquisada e aparecem na descrição da manifestação fenomênica de inúmeras relações entre humanos e demais animais. As modalidades de relação são: a relação naturalizada e a relação não naturalizada.

A relação naturalizada é aquela na qual o animal é objetificado por uma pretensa utilidade para o homem e é desprovido daquilo que o caracteriza e o identifica em essência: sua animalidade. Essa essência é perdida ou ignorada nesse pragmatismo naturalizado. Essa modalidade de vínculo utilitário é descrita por Borba (2015).

A outra possibilidade de relação consiste em uma relação não naturalizada, no qual o animal ainda é intencionado em sua essência, e não um mero fim para um meio ou um objeto, uma ferramenta qualquer. Ele encontra em si mesmo a sua razão, e não é precisamente dotado de sentido por qualquer atributo ou causa externa.

Assim, verifica-se que a concepção do que é o animal diante das duas modalidades de vínculo diferem entre si, e configuram-se enquanto embasamento para as diferentes relações. Portanto, é preciso compreender como essas concepções foram construídas e permitem o estabelecimento de certas relações e vínculos. 
Desse modo, configura-se a primeira evidência, marcadamente contraditória no discurso científico que demostra a perda do sentido da relação entre humanos e demais animais. O ser humano, por mais que seja considerado um animal, aos olhos da ciência, e tenha uma origem comum a dos demais animais, assim como lhe confira algum grau de parentesco (DESMOND; MOORE, 2008), não se considera na história do pensamento ocidental enquanto um animal. Ou ainda, caso considere-se um animal, considera-se um animal diferenciado. Está vedado à natureza e às propriedades comuns compartilhadas por ambos.

Para encontrar as evidências, deve-se suspender o pressuposto e realizar as reduções, para que o fenômeno possa ser intuído. Desse modo, a leitura deve ser realizada com todo o rigor fenomenológico. As evidências dessa emancipação são os seguintes: a concepção primeira e original da nossa relação com os animais; a história do pensamento ocidental e os pensadores que produziram acerca dessa questão; a utilização na linguagem de termos exclusivos e maneiristas que comprovam o fenômeno; o estereótipo da animalidade quando direcionada ao humano; o não reconhecimento das habilidades animais; a exploração animal e o desmerecimento das evidências que nos dirigem de novo à animalidade.

Dito isto, é oportuno elucidar que em inúmeras sociedades, em especial com organizações paleolíticas, não existia diferenciação estrita entre os seres humanos e os demais animais. Os animais poderiam ser compreendidos nessas sociedades como seres divinos, protetores e partes da família pela organização totêmica. De modo que mesmo um ser humano poderia reencarnar em um corpo animal (ROCHA, MUÑOZ E ROMA, 2016).

Nesse mundo e natureza compartilhados, como até a atualidade nas religiões xamanistas e nos povos inuit, o animal ocupa um lugar comum na existência. O processo de verticalização, emancipação e hierarquização tem início com a neotelização dos povos, que começam a instrumentalizar a natureza, e por consequência os demais animais (ROCHA, MUÑOZ E ROMA, 2016).

A partir da instrumentalização e do domínio técnico sobre a natureza, o pensamento ocidental tomou como pressuposto o ser humano como uma espécie que transcendia a 
animalidade. Nesse ponto, inúmeros pensadores que buscaram embasar a soberania humana, procurando a diferença essencial que faria do humano um animal diferente dos demais.

Dentre tais pensadores, podemos citar: Aristóteles, J. Lacan, R. Descartes, I. Kant, M. Heidegger, E. Levinás, Max Scheler e F. Nietzsche (DERRIDA, 2002; NIETZSCHE, 1998; SCHELER, 2008). E embora exista uma resposta comum, de pôr a linguagem como elemento essencial e diferencial da humanidade em decorrência dos demais animais, não existe um consenso absoluto.

Isso porque Max Scheler (2008) argumenta que a diferença entre o humano e os demais animais vai para muito além dessa qualidade individual; Nietzsche (1998), afirma que o Homo Sapiens é um animal autobiográfico; Derrida (2002) demonstra que os animais não são isentos de linguagem, mas a humanidade os tirou o direito à resposta; e Ingold (1995) apresenta que vários animais possuem tipos específicos de linguagem e comunicação.

Logo, nunca houve um consenso definitivo sobre o tema; isso se deve ao fato de que as tentativas de descrição e apreensão da essência humana se deram em uma prerrogativa comparativa, ou seja, buscaram a essência humana na comparação com os demais animais, ao invés de buscá-la no ser humano.

Isso ocorre porque o humano já foi pensado previamente como hierarquicamente superior pela razão ocidental; o que levou aos inúmeros pensadores a categorizar e tipificar o a espécie Homo Sapiens em uma seção a parte. O que garante ao animal um lugar inferior, e ao humano, o não reconhecimento de sua animalidade. Não é sem sentido que o termo animal, quando dirigido a um ser humano, tem conotação pejorativa.

Vide o caso narrado por Almeida e Mota (2015), quando um jogador foi discriminado por ser comparado a um animal; ou mesmo Darwin que foi ironizado em uma caricatura com sua cabeça pertencente a um corpo de macaco (DESMOND; MOORE, 2008). E ainda, quando a certos fenótipos humanos eram considerados como pertencentes à outra espécie, o que legitimava sua utilização laboral forçada, sua escravidão. 
O fenômeno da escravidão se valeu da hierarquização das espécies, tanto na antiguidade, quando foi defendida por Aristóteles (TOSI, 2003); quando pela razão científica moderna, que se embasava erroneamente em teorias darwinistas para justificar tais atos (DESMOND; MOORE, 2008). E aqui o fenômeno se evidencia em Borba (2015), ao comparar a situação do animal na relação naturalizada com a de um escravo.

O que nos conduz aos pontos centrais dessa compreensão e dessa relação naturalizada: O humano, historicamente, se compreendeu como emancipado e por isso buscou determinar-se hierarquicamente acima dos demais animais, o que se reflete também a ele não se referenciar unicamente enquanto animal, por mais que pertença à taxonomia desse reino e possua parentesco genético de até 90\% com certas espécies (INGOLD, 1995); e o Homo Sapiens, ao ocupar esse lugar, legitimou um modelo de relação com os demais animais que perpetua a exploração para finalidades objetais, evidência que se confirma com a necessidade de obras como as de Ingold (1995), Peter Singer (2004), Desmond e Moore (2008) relembrarem constantemente o nosso parentesco e pertencimento ao reino animal, já confirmado, inclusive pelo saber científico, mas que o processo de naturalização deturpa constantemente; e pela etimologia, já que anima remete àqueles que realizam movimentos e respiram (FONSECA, 2008).

Assim, corrobora a fenomenologia husserliana ao afirmar que "o naturalismo é doutrinador, pregador, moralista, reformador" (HUSSERL, 1965. p. 11). E ainda que o sentido da fenomenologia está em reaver o sentido do conhecimento gerado pela ciência para uma proposta ética (CAVALIERI, 2010).

Em suma, o que se evidenciou da relação naturalizada entre o humano e os demais animais foi que a essência dessa relação é a concepção do animal enquanto objeto que serve à humanidade. Ou seja, o que se evidenciou dessa relação através da pesquisa é que a essência do animal é perdida para o racionalismo naturalista, e este passa a ser concebido meramente como um meio para um fim, fazendo com que o verdadeiro sentido da relação se perca.

Existem alguns exemplos que evidenciam e permitem-nos intuir como a relação naturalizada com os animais os tem como objetos, além de perder seu sentido e compromisso ético. Estas relações que servem de exemplo são: a experimentação, a 
comercialização, o fenômeno do abandono e a TAA's referenciada na literatura enquanto puramente uma técnica.

Desse modo, temos primeiramente a experimentação com animais que parte da racionalização de que a experimentação animal traz potencial avanço à ciência de modo que pode salvar vidas, e que inclusive seria antiético livrarmos por completo dela, visto seus ganhos potenciais e as vidas que seriam salvas (MENEZES FILHO; GURGEL, 2011). Contudo, muitas das experiências realizadas, além de cruéis e desumanas, não trouxeram e nem objetivaram trazer nenhum ganho potencial para a humanidade.

Por exemplo, drogas foram injetadas em diversos animais, unicamente com a finalidade de observar os resultados, sem nenhuma pretensão médica. Evidencia-se a falta de intenção de se propiciar avanços na medicina nesses casos visto que: alguns animais eram demasiadamente distantes, em termos taxonômicos, dos seres humanos, como as aranhas; e em outros, a quantidade de drogas ilícitas aplicadas nesses animais foi tão elevada que eles faleceram de overdose (BOESE, 2007). Demonstrando, assim, que o animal foi objetificado, sem nenhuma atenção ao seu bem-estar ou segurança, e que o sentido do conhecimento que pretendia ser produzido por esses experimentos não configurava nenhum sentido para a humanidade ou senso ético.

Quanto à comercialização, Pastori e Matos (2016), sinalizam para a dualidade existente entre a grande aquisição de animais domésticos por via do comercio nos petshops, e dos registros de abandonos. Sinalizam ainda que o animal doméstico é adquirido com um objetivo especifico de fazer companhia e oferecer afeto, um afeto incondicional. Contudo, assim que o ônus de arcar com a mascote surge, esse animal é irresponsavelmente descartado e abandonado pelo dono. Em contrapartida, mesmo com um número alto de animais abandonados, que poderiam ser fontes de carinho e afeto, o mercado de mascotes continua crescendo, já que o animal-produto é também símbolo de ostentação.

O resultado direto desse modelo de relação quando estendido à TAAs tem como consequência uma técnica que, tomada pela essência dessa relação, ver o animal como ferramenta, como um meio para atingir um fim: a melhora da saúde humana. As 
evidências para tal fenômeno são textos de produção científica, tais quais Aguiar e Silva (2011); Kawakami e Nakano (2002) e Carvalho et al. (2011), por exemplo.

Tais produções visam sempre o benefício humano em primeiro lugar; quando remetem ao bem-estar animal, este bem estar é avaliado por critérios humanos e não por manifestações volitivas do próprio animal; referem-se ao animal como recurso; preferenciam certas raças e espécies, predileção pelos adestrados; quando a relação entre humanos e demais animais é referenciada, é sempre objetivando os benefícios para o ser humano, que terá atenção e afeto advindo deste animal.

Todos esses pontos supracitados demonstram dois aspectos fundamentais da terapia quando o modelo de relação é naturalizado: O primeiro ponto é que o animal é entendido como objeto, e sua essência obscurecida, como se existissem animais e raças específicas e próprias para geração de vínculo e para a terapia, o que contradiz o começo das TAAs, visto que diversos animais já foram historicamente utilizados (DOTTI, 2014); É um modelo de terapia que, embora possua certa eficácia, utilizando o animal como ponte ou permitindo formas de análise, é um processo que não explora toda a potencialidade dessa relação ou ainda que desconhece o efeito do vínculo para a obtenção dos resultados esperados.

O animal, na relação naturalizada, é e só pode ser utilizado para: ou gerar resultados específicos e diretos que tenham finalidades dentro dos objetivos terapêuticos, ou seja, a TAA é indicada e praticada visando e objetivando meramente objetivos próprios e validados pela ciência; ou propiciar um ambiente onde se observe os modos do paciente em se relacionar e interagir com o animal, e a partir daí, possibilitar análises e acesso ao vivido, como ocorreu, por exemplo, no caso do psicólogo Boris Levinson, no qual o seu cão invadiu seu consultório durante um atendimento infantil, e ele obteve dados observando a interação entre seu paciente e o cachorro (DOTTI, 2014).

Assim, todas essas manifestações já supracitadas, auxiliam-nos no processo de variação imaginativa e elucidam que estas decorrem da tomada do animal como objeto, sendo esta uma característica essencial dessa modalidade de relação. Ou seja, em todos esses fenômenos, essa é uma característica comum, e que implicam em uma manifestação 
sem empatia, alteridade e respeito ao animal e suas manifestações próprias e espontâneas.

Verificamos, portanto um processo de relação que não seja naturalizado, ou seja, que impliquem na concepção real de um vínculo entre humanos e demais animais, e como esses modos desse vínculo permitem uma prática terapêutica além das já supracitadas, no vínculo naturalizado. Dessa forma, vários são os benefícios apontados e que, pela visão naturalista, sustentam a prática da TAA: diminuição do estresse, possibilidade de comunicação, engajamento, redução da pressão arterial, incentivo ao exercício físico, redução da ansiedade, satisfação de necessidades psicológicas e etc... (DOTTI, 2014; AGUIAR; SILVA, 2011, KAWAKAMI; NAKANO, 2002; CARVALHO et al., 2011). Porém, todos esses resultados provêm de algo do que a ciência natural não permite dar conta, pois é algo que escapa ao objetivismo material e mensurável.

Nenhum resultado verdadeiro pode ser atingido por meio da naturalização dessa relação, mas antes do vínculo obtido por meio de uma relação na qual o animal não é mero objeto. Ou seja, o animal nessa relação é concebido à consciência e compreendido com outro sentido: não mais objeto, mas agora um outro ${ }^{3}$. É oportuno situar que a noção do conceito de outro na fenomenologia, em especial situadas em Husserl e E. Levinas consiste no reconhecimento de uma alteridade radical, na compreensão de que existe outra vida que é também presente no mundo, e a essa outra existência somos convocados a reconhecer quando ocorre o encontro (PELIZZOLI, 1994). Assim, toda manifestação anímica realizada por outro ser, é um outro. Afinal, Goto (2007) já situa que o objeto de estudo da psicologia fenomenológica é o ser anímico, desse modo, qualquer fenômeno intuído enquanto outro, e não meramente enquanto ente, exige um direcionamento ético durante o contato.

\footnotetext{
3 Sobre a categoria Outro os autores ratificam que ela é essencial para a Fenomenologia e Psicologia Fenomenológica, pois Husserl $(1929 / 2001 ; 1929 / 2013)$ afirma ser o outro, um alter ego, um outro eu, análogo a mim, não sendo eu, mas sempre em relação a mim. Relação esta que na ausência ou na presença é sempre co-relação, por isso posso captar o outro (seja ele humano ou animal) como um outro eu pela entropatia ou empatia (Einfühlung) quer dizer sinto a experiência de um outro ser humano ou não humano pela sua apreensão imediata. Do ponto de vista fenomenológico, Husserl (1929/2001) orienta que os outros não são sempre concebidos como objetos (coisas naturais), mas como outros eus/alter egos.
} 
O que implica necessariamente que ele para de ser posto na lógica anterior do discurso da diferença, e passa a ser compreendido em si mesmo, e nessa compreensão ele é retirado da lógica demonstrada por Ingold (1995), que é a lógica da compreensão do animal pela diferença e a hierarquia antropocêntrica, na qual o animal é posto em uma posição inferior. È só quando concebido nessa posição de outro que se pode então relacionar-se verdadeiramente, e que a ocorrência de afeto e a implicância de uma concepção ética é posta e estendida para o animal.

Tal prerrogativa parte dos próprios princípios normativos da ética enquanto uma prática de convivência social, a ética sem o outro é impossível (VALLS, 1994). Ou seja, é impossível uma ética estendida ao animal se eles forem compreendidos como objetos.

Desse modo, em uma relação marcada pelo o animal reconhecido como outro, não só é possível obter tudo aquilo que a ciência já metrifica e compreende como resultados positivos da TAAs: diminuição do estresse, possibilidade de comunicação, engajamento, redução da pressão arterial, incentivo ao exercício físico, redução da ansiedade, satisfação de necessidades psicológicas e etc (DOTTI, 2014; AGUIAR; SILVA, 2011, KAWAKAMI; NAKANO, 2002; CARVALHO et al., 2011). Mas, também permite uma manifestação fenomênica que vai para além dessa metrificação naturalística, o animal compreendido como outro e estando em relação com esse sujeito desperta um sentido de cuidado com o outro e de autocuidado, como também é capaz de dar sentido à existência, mesmo que outrora, adoecida; e que é justamente essa manifestação que implica nos resultados já comprovados pela ciência.

Analisaram-se dois casos de uma relação entre humanos e demais animais nos quais o animal foi reconhecido enquanto outro e foi tomado como outro na relação, atribuindo um sentido para esse sujeito que, passou a dirigir-se para o mundo de outra forma. Tais casos não só evidenciam uma modalidade comum de relacionamento, como também permitem o procedimento descritivo do fenômeno e a variação imaginativa, que nos permitem compreender as estruturas essenciais do fenômeno.

O primeiro caso é um auto relato de Browen (2013), que se recupera do seu vício em heroína após entrar em contato com um gato. O reconhecimento desse gato enquanto outro permitiu uma relação afetiva que se manifestava como cuidado, não só com o 
outro, mas também consigo mesmo, já que ele agora tinha uma responsabilidade para e com o gato. Essa manifestação de cuidado, além de ser autoevidente no relato, traz consigo uma mudança na intencionalidade do sujeito para com o mundo.

Outro exemplo é o caso de um paciente psiquiátrico, diagnosticado com esquizofrenia que foi paciente da psiquiatra brasileira Nise da Silveira. Esse caso está presente na sua biografia, escrita por Mello (2014). Em suma, esse paciente desenvolveu um vínculo com um cachorro vira-lata - o que evidencia a não importância da raça para o processo terapêutico - durante seu período no hospital psiquiátrico Dom Pedro II; em certo episódio, quando esse cão feriu-se, o paciente, preocupado e manifestando o cuidado e o afeto que tinha para e com esse cão, solicitou dinheiro para ir à farmácia obter medicamentos e utensílios para tratar e fazer um curativo no ferimento do cão. Ele foi sozinho à farmácia, comprou o necessário, voltou e entregou corretamente o troco; acrescenta-se que pediu o dinheiro com esse objetivo expressando-se de forma exemplar.

Percebamos os pontos evidenciados em comum em ambos os casos, e a expressão do cuidado e a presença da intencionalidade de ambos os sujeitos e como ela se alterou frente ao mundo e os fez transcender aquele fenômeno da sua existência adoecida quando Ihes foi necessário. Isso, que é evidenciado tão claramente em ambos os casos não só é mais importante, por ser originário e ser causa primeira, dos benefícios do TAAs, como não está presente em nenhum artigo científico que aborde o tema sob a metodologia científica e natural.

Desse modo, podemos ainda apontar que nesse modo de relacionamento e vínculo, existe a presença de empatia, alteridade e respeito pelo outro-animal. E mais, dentro da concepção de uma clínica e terapêutica fenomenológica, o cuidado e a sua expressão consigo e com o outro é compreendido como uma forma de sucesso terapêutico e de cura, enquanto forma de existir (SÁ, 2002).

Da mesma forma, uma manifestação enquanto agressividade e violência para com os animais, apenas ressalta um modo de existência adoecida, presa na manifestação de um mal estar, ou de um prazer indevido, que só encontra vias por meio da violência e agressão daquilo que é, então, objeto - pois não há empatia ou alteridade - e que, ao 
contrário do vínculo enquanto cuidado, não evidenciam abrir uma nova possibilidade ou potencialidade de dirigir-se ao mundo, mas antes um afastamento dele.

Assim, conforme o caso do grande massacre dos gatos (DARNTON, 1989), a violência é a manifestação de mal-estar, e o prazer ao causar sofrimento àqueles que faziam sofrer. Esse grande massacre refere-se a um assassinato em massa, realizado por operários, que mataram vários gatos de seus patrões como forma de puni-los pelos abusos. Nota-se a evidência clara do gato, não enquanto outro - digno de empatia e respeito - mas tomado como instrumento para um fim, e nota-se também a forma como estes empregados já estavam, antes de tudo, adoecidos pela relação abusiva com seus empregadores.

Contudo, o avanço legal que garante o cuidado e a proteção dos demais animais, já pode ser compreendido como um avanço da sensibilidade e da ética humana, que começa a intuir, perceber e reconhecer o animal, não mais como objeto, mas como outro. Se não por isso, as legislações, como as trazidas por Adede y Castro (2006), não teriam sentido algum.

Aqui seguem os resultados finais, quanto às modalidades de relação, ao vínculo e ao procedimento terapêutico: Os demais animais hoje foram objetificados e instrumentalizados pela humanidade, que se distanciou da sua própria animalidade; essa relação que se presencia em uma postura natural é a causa de inúmeros fenômenos que apenas evidenciam essa postura e esse descaso; quando a postura natural e o conhecimento científico se direcionam ao fenômeno da TAAs, deixam escapar o principal, ressaltando apenas o que pode ser metrificado enquanto evidência de benefícios da prática. Contudo, uma prática proposta nos modelos naturais vê o animal como recurso e como instrumento, o que ainda é condizente com a postura que objetifica os animais, e tal postura não só encobre o verdadeiro fenômeno da terapêutica, como também limita seu exercício e sua compreensão em aspectos mais profundos, evidenciados pelo animal enquanto outro. 


\section{Considerações finais}

Compreendemos assim que a relação entre humanos e demais animais tem sido modelada por uma imposição hierárquica e instrumental baseada na modelo de racionalidade científica natural. O que implica em uma série de desdobramentos que acarretam na objetificação do animal, possibilitando atuações especistas que a naturalização dos maus-tratos.

Compreende-se também a própria constituição da imagem ocidental de ser humano ao tentar, equivocadamente, se compreender acima e com base comparativa aos demais animais. O que também reflete as estruturas hierárquicas dentro das próprias relações humanas de racismo e discriminação, por exemplo.

E mais, compreende-se ainda que o vínculo primordial entre seres humanos e demais animais foi perdido na medida em que o Homo Sapiens passou a instrumentalizar a natureza - e os animais nela presentes. Desse modo, não só o advento da modernidade, mas do pensamento ocidental de uma forma geral configura-se no que se manifesta em uma negação ou esquecimento do pertencimento do humano à sua origem comum, no mundo, com os demais animais e às suas relações com eles.

Assim, delimitamos também uma barreira epistemológica para as TAAs, quando estas se tornam ramos dos estudos das ciências naturais. O vínculo acaba sendo ocultado, pois o que se evidência são seus efeitos metrificáveis e mensuráveis da interação entre humanos e demais animais. Portanto, o conhecimento científico perdeu, não só o seu sentido ético originário - ao determinar o animal como meio para um fim, e, portanto, um recurso - como também perdeu o fenômeno mais importante na delimitação de seu objeto de estudo.

Para tanto, percebemos que ainda existe algum movimento e sensibilidade humana, tanto nos casos de vínculos bem estabelecidos e éticos, presentes na literatura, e também evidenciados nos avanços jurídicos dentro da causa animal. Assim, conceber o animal como um outro, dentro de uma relação, estabelecendo um vínculo, parece restaurar em nós a nossa própria humanidade, na medida em que a construímos e que nos consideramos seres capazes de utilizar adequadamente a razão. 
Não sem razões, o reconhecimento animal e a nossa sensibilidade e reconhecimento para com o outro, parecem despertar o que há de mais humano em nós. A incrível contradição é que, evidencia-se que teremos que recuperar nossa animalidade ao reconhecer os demais animais como outros, para que possamos nos considerar mais humanos, ao sermos bons, dignos e justos com eles. Enfim ser empáticos com eles.

Tal reconhecimento implica diretamente em uma proposta de intervenção terapêutica que se fundamente prioritariamente na possibilidade de um vínculo entre humanos e demais animais, e nas profundas mudanças que esse vínculo pode gerar, sejam elas, mensuráveis ou não, mas sempre vivenciadas originalmente na relação. E mais, que novos estudos sejam feitos e desenvolvidos com rigor epistemológico, utilizando-se de formas alternativas de pesquisa ao modelo científico natural, certamente capazes de dar conta da construção de um conhecimento que vá para além dos atuais modelos epistemológicos já consagrados.

\section{Referências}

ADEDE Y CASTRO, J. M. Direito dos Animais na Legislação Brasileira. Porto Alegre: Sergio Antonio Fabris Ed., 2006.

AGUIAR, S. M. H. C. Á; SILVA, R. B. P. Humanização na assistência odontológica de pessoas com deficiência, através do projeto Cão Cidadão-Unesp. Revista Ciência em Extensão, v. 7, n. 1, p. 117-125, 2011.

ALMEIDA, P. H. S.; MOTA, C. M. L. Redes sociais e identidade nacional: a força de um gesto. Animus. Revista Interamericana de Comunicação Midiática, v. 14, n. 28, 2015.

BARBOSA, J. A. Reflexões sobre o método. Itinerários - Revista de Literatura, Araraquara, n. 24, 15-31, 2006.

BARBOSA, R. B. A Ideia Husserliana de Fenomenologia. Inconfidentia - Revista Eletrônica de filosofia. Mariana, v. 2, n. 2, jan-jun, p. 21-40, 2014.

BOESE, A. Elephants on Acid: and other bizarre experiments. Mariner books: 2007.

BORBA, J. M. P. Saúde na Infância, Medicalização da existência e as Intervenções Assistidas com Animais: alternatica ou "nova" tecnificação. In: A Infância Medicalizada: discursos, práticas e saberes para o enfrentamento da medicalização da vida. Curitiba: Editora CRV, 2015. 
BROWEN, J. Um Gato de rua Chamado Bob. Ribeirão Preto, SP: Editora Novo Conceito: 2013.

CARVALHO, C. F. et al. Uso da atividade assistida por animais na melhora da qualidade de vida de idosos institucionalizados. Uberlândia, Em Extensão, v. 10, n. 2, 149-155, 2011.

CASTRO, T. G. de; GOMES, W. B. Movimento fenomenológico: controvérsias e perspectivas na pesquisa psicológica. Psicologia: teoria e pesquisa, Brasília. v. 27, n. 2, p. 233-240, 2011.

CAVALIERI, E. O rigor científico como questão ética em Edmund Husserl. In: KURTH, V. S.; SANTOS, T. (orgs.). IV Seminário Internacional de Pesquisa e Estudos Qualitatiovos - Pesquisa Qualitativa: rigor em questão. 1 ed. Rio Claro: UNESP, 2010, v. 1, p. 648 658.

DARNTON, R. O massacre dos gatos. São Paulo: Companhia das Letras, 1989.

DERRIDA, J. O animal que logo sou. Trad. Fábio Landa. São Paulo: Unesp, 2002.

DESMOND, A.; MOORE, J. A causa sagrada de Darwin. Rio de Janeiro: Record, 2009.

DOTTI, J. Terapia \& animais. São Paulo: Livrus, 2014.

FEIJOO, A. M. L. C. de; GOTO, T. A. É Possível a Fenomenologia de Husserl como Método de Pesquisa em Psicologia? Brasília, Psicologia: Teoria e Pesquisa, v. 32, n. 4, p. 01-09, 2017.

FONSECA, J. T. Sobre literatura, crianças, adultos e outros bichos. Boletim de Pesquisa NELIC, v. 1, n. 1, p. 57-61, 2008.

FERREIRA, E. C. O sentido fenomenológico da noção de redução em Edmund Husserl: a relação entre transcendental e natural. 2008. 134 p. Dissertação (Mestrado) Programa de pós-graduação em Filosofia. Universidade Federal de Santa Catarina, Florianópolis, 2008.

GIORGI, B. Reflections on therapeutic practice guided by a Husserlian perspective. Journal of Phenomenological Psychology, v. 36, n. 2, p. 141-194, 2005.

GOTO, T. A. A (re) constituição da psicologia fenomenológica em Edmund Husserl. Campinas, 2007. 218p. Tese de Doutorado - Curso de Pós-graduação em Psicologia, Pontifícia Universidade Católica de Campinas. Campinas, 2007.

Introdução à psicologia fenomenológica: a nova psicologia de Edmund Husserl. São Paulo: Paulus, 2015.

GUIMARÃES, A. C. Aproximação aos conceitos básicos da fenomenologia. Cadernos da EMARF, Fenomenologia e Direito: Rio de Janeiro, v. 6, n. 1, p. 35-46, 2013.

HUSSERL, E. A ideia da fenomenologia. Tradução Artur Morão. Rio de Janeiro: Edições 70, 2000. 
2001.

Meditações Cartesianas: Introdução à Fenomenologia. São Paulo: Madras,

Meditações Cartesianas e Conferências de Paris: de acordo com o texto de Husserliana I. Rio de Janeiro: Forense, 2013.

Investigações Lógicas: prolegômenos. Rio de Janeiro: Forense, 2014.

A filosofia como ciência de rigor. Lisboa: Atlântida, 1965.

A Crise da Humanidade Europeia e a Filosofia. Tradutor: Pedro M. S. Alves. Colecção Textos Clássicos de Filosofia: Covilhã, 2008.

INGOLD, T. Humanidade e animalidade. Revista Brasileira de Ciências Sociais, v. 28, n. 10, 1995.

KAWAKAMI, C. H.; NAKANO, C. K. Relato de experiência: terapia assistida por animais (TAA)-mais um recurso na comunicação entre paciente e enfermeiro. In: Proceedings of the 8. Brazilian Nursing Communication Symposium. 2002.

MELLO, L. C. Nise da Silveira: caminhos de uma psiquiatra rebelde. Rio de Janeiro, Automática Edições, 2014.

MENEZES FILHO, A. de S.; GURGEL, W. B. Ética, método e experimentação animal: a questão do especismo nas ciências experimentais. Cadernos de Pesquisa. São Luís, v. 18, n. 3, p. 40-53, set-dez, 2011.

NEVES, J. L. Pesquisa qualitativa: características, usos e possibilidades. Caderno de pesquisas em administração. São Paulo, v. 1, n. 3, p. 01-05, 1996.

NIETZSCHE, F. Genealogia da moral. Tradução: Paulo Cesar de Souza, São Paulo:

Companhia das Letras. 1998.

PASTORI, É. O.; DE MATOS, L. G. Da paixão à "ajuda animalitária": o

paradoxo do "amor incondicional" no cuidado e no abandono de animais de

estimação. Caderno Eletrônico de Ciências Sociais. Vitória, v. 3, n. 1, p. 112-132, 2016.

PELIZZOLI, Marcelo Luiz. A relação ao outro em Husserl e Levinas. Edipucrs, 1994.

ROCHA, C. F. P. G.; MUÑOZ, P. de O. L.; ROMA, R. P. S. História do Relacionamento entre animais humanos e não humanos e da TAA. In: CHELINI, M. O. M.; OTTA, E (orgs.). Terapia Assistida Por Animais. São Paulo: Editora Manole Ltda, 2016.

SÁ, R.N. de. A noção heideggeriana de cuidado (Sorge) e a clínica psicoterápica. Revista de

Filosofia Veritas, v. 45, n. 2, p. 259-266, 2002.

SCHELER, M. A Diferença Essencial entre o Homem e o Animal. In: A situação do

Homem no cosmos. Texto \& Grafia: Lisboa: 2008. 
SINGER, P. Libertação Animal. Porto Alegre, RS: Lugano, 2004.

TOSI, Giuseppe. Aristóteles e a escravidão natural. Boletim do CPA, Campinas, n. 15, p. 71-100, 2003.

VALLS, Á. L. M. O que é ética. São Paulo: Editora Brasiliense, 1994.

ZILES, U. Fenomenologia e teoria do conhecimento em Husserl. Rev. abordagem

gestalt, Goiânia, v. 13, n. 2, p. 216-221, dez. 2007.

A fenomenologia husserliana como método radical. In: HUSSERL, Edmund.

A crise da humanidade europeia e a filosofia. Porto Alegre: EDIPUCRS,

2008. p. 11-57.

Recebido em 30/10/2017

Aprovado em 01/08/2018 